\title{
Heat of hydration of low-clinker cements
}

\section{Part I. Semi-adiabatic and isothermal tests at different temperature}

\author{
Barbara Klemczak ${ }^{1}$ - Maciej Batog ${ }^{1}$
}

Received: 26 January 2015 / Accepted: 13 May 2015 / Published online: 20 June 2015

(c) The Author(s) 2015. This article is published with open access at Springerlink.com

\begin{abstract}
The hydration heat evolution of low clinker cements is studied in a dependence on the testing method and temperature. Four substitution rates of ordinary Portland cement by ground granulated blast furnace slag or siliceous fly ash were used-10, 30, 50 and $70 \%$. In all cases, the water/binder ratio of the cement paste was 0.5 . The heat evolution and the heat evolution rate were monitored over $72 \mathrm{~h}$ with the use of two testing methods. The isothermal measurements were carried out with the use of TAM Air isothermal calorimeter at 20 and $50{ }^{\circ} \mathrm{C}$. The heat evolution was also determined with the use of a semiadiabatic calorimeter. Part I of the paper presents the results of the experimental tests and discussed the influence of mineral additives on the hydration heat evolution.
\end{abstract}

Keywords Low-clinker cement - Slag · Fly ash · Hydration heat · Isothermal heat flow · Semi-adiabatic heat flow

\section{Introduction}

The time development of the hydration heat of cements belongs to the important topics studies in concrete science. A knowledge of the hydration heat evolution $\left(\mathrm{J} \mathrm{g}^{-1}\right)$ as well as the heat evolution rate $\left(\mathrm{J} \mathrm{g}^{-1} \mathrm{~h}^{-1}\right)$ is necessary in those issues when exothermic nature of the hydration

Barbara Klemczak

Barbara.Klemczak@polsl.pl

Maciej Batog

Maciej.Batog@polsl.pl

1 Faculty of Civil Engineering, Silesian University of Technology, Akademicka 5, 44-100 Gliwice, Poland process can lead to a significant temperature increase inside the concrete structure. Temperature variations related to the exothermic nature of cement hydration are especially hazardous in massive concrete structures [1-5]. In such structures, due to the poor thermal conductivity of concrete, high temperature gradients may occur between the interior and the surface of structural elements. In massive concrete structures, the internal temperature can reach a significant level because the curing conditions are close to adiabatic and maximum temperature can reach even 50-70 ${ }^{\circ} \mathrm{C}$ [1-8]. The volume changes due to temperature variation have consequences in arising stresses in the concrete element. When the tensile stress exceeds, the tensile strength of the concrete cracks can be observed in a structural member. Early-age cracking of thermal origin is usually considered as a durability issue because it can initiate corrosion of reinforcement. Additionally, the temperature exceeding $65-70{ }^{\circ} \mathrm{C}$ which may develop in the massive structures can lead to the delayed ettringite formation (DEF) and consequently to possible damage of concrete [5].

The complex variables that affect the temperature rise in the massive structure are thermal properties of early-age concrete, environmental conditions during concreting and curing of concrete $[5,8,9]$, dimensions and geometry of concrete structure [10]. One of particular importance is the rate of hydration heat evolution. Hence, the basic method to reduce negative effects of self-heating of structures is the use of the cements with moderate and low heat of hydration. In this respect, the use of the low-clinker cements is motivated by the benefit as reducing the evolved heat, which in turn reduces the in-place concrete temperatures. In such cements, a certain portion of clinker is substituted with mineral additions. The most common mineral additions are ground granulated blast furnace slag (GGBFS), 
which is a by-product of iron manufacturing process and fly ash stems from the pollution-control equipment of coalburning power plants. The mineral additions can be used in two different ways. Mineral additions may substitute part of Portland clinker at the stage of cement production and the resulting product is called "blended cement" or "composite cement." It is also possible to replace the part of the clinker with GGBFS or fly ash at the concrete batch plant, and then, these mineral additions are usually described as supplementary cementitious material (SCM).

The use of these materials also has a positive impact on the environment in many aspects. One of them is to mitigate $\mathrm{CO}_{2}$ emissions from the production of cement clinker into the atmosphere. Another advantage is connected with the recycling of waste materials what undoubtedly contributes to a cleaner environment. Other benefits in terms of durability of concrete can be also achieved, e.g., by varying the proportions of the blend, attributes such as sulfate resistance and resistance to alkali silica reaction can be attained with blended cement.

The hydration heat evolution of cements with mineral additions has been a subject of extensive investigations within the past several years. The hydration heat of blended cements has been investigated by several authors [11-31]. The hydration of blended cements with different substitution rates of GGBFS has been studied, inter alia, by Roy and Idorn [11], De Schutter [12, 13], Escalante et al. [14], Saeki and Monteiro [15], Pane and Hansen [16], Binici et al. [17], Meinhard and Lackner [18], Ježo et al. [19], Chen et al. [20], Merzouki et al. [21], Hana et al. [22], Gruyaert et al. [23] and Siler [24]. It has been observed in these tests that the evolved heat decreases as slag content increases, but at the same time the heat evolved increases with the fineness of the slag or clinker in the blended cements. Simultaneously, mixtures containing GBFS do not generate higher heat initially, but they generate heat higher than the OPC pastes in the later period [24]. The tests performed at different temperature showed that higher curing temperature increased the reactivity of the slag and a decreased reactivity with an increase in the percentage of slag replacement.

For composite binders containing fly ash, the hydration heat evolution has been studied, inter alia, by NocunWczelik [25-27], Pacewska et al. [28-30], Giergiczny [31, 32], Han et al. [22], Kumar et al. [33], Narmluk et al. [34] and Mounanga et al. [35]. Similarly, as for slag cements, the tests showed that the evolved heat decreases with increasing amount of fly ash addition. It has been also shown that in case of large amount of fly ash, obtained curves of heat release are more flat and extended in time compared with calorimetric curves obtained for ordinary Portland cement. The duration of an induction period is also prolonged, which means the hydration products are formed slower. Kumar et al. [33] reported that the addition of fly ash retards the hydration process while raising temperature accelerates it. Narmluk et al. [34] found that fly ash retards the early hydration of cement but accelerates the hydration of cement in the later period at 20 and $35^{\circ} \mathrm{C}$, but at $50{ }^{\circ} \mathrm{C}$ and $50 \%$ dosage of fly ash retards the hydration of cement at later age as well. Nevertheless, it is highlighted that the influence of fly ash addition on the hydration process can be different and it is dependent on the mineral composition and fineness of fly ash [25-35]. The kinetics and mechanism of hydration in different cementitious systems with fly ash has been also discussed in [25]. The tests results reported in this paper show different sensitivity of cements to fly ash admixture on the hydration process, the influence of phase composition, alkali content and fineness of cement on the heat evolution has been evidenced.

In Part I of the paper, the hydration heat evolution of the cements with different amount of ground granulated blast furnace slag or siliceous fly ash is studied in a dependence on the testing method and temperature. A brief description of the methods of measuring the heat of hydration is also included.

\section{Heat flow measurement methods}

Nowadays, there are four commonly used test methods to determine the heat released during the hydration process. The first methods of measuring the hydration heat evolution were developed in the $30 \mathrm{~s}$ of last century when first dams were built in USA and the problem with high temperatures arising during the hardening of concrete came to be known. The solution calorimetry and isothermal conduction calorimetry method were these first methods. Later, the adiabatic and semi-adiabatic methods were developed. A brief description of these methods with their advantages and limitations is presented below.

\section{Solution calorimetry}

In this method, a tested sample and reference sample with fully hydrated cement are dissolved in a mixture of hydrofluoric and nitric acid. Dissolution is carried out in Dewar vessel (semi-adiabatic conditions), and the temperature rise is measured during the dissolution process. On the basis of registered temperature, the amount of heat is calculated, similarly as in semi-adiabatic method. The difference between heat released by the tested sample and the reference sample is an examined heat of hydration. The principle that the potential chemical energy in a material can be measured by the heat liberated when the material is decomposed into the basic chemical components is exploited in this method. It is standardized method (ISO 29582-1 [36], EN 196-8 [37] and ASTM C186-13 [38]). 
The advantage of this method is the possibility of measuring the amount of heat evolved over long periods of time, because the heat is measured directly in relation to a reference sample. This test method has also some disadvantages as the work with toxic and hazardous acids, which must be protected by stringent safety regulations. This makes that this method is labor intensive. The method is also sensitive and cannot give sufficiently good results if a mixture of acids is not able to dissolve the tested sample and reference sample to the same level.

\section{Isothermal conduction calorimetry}

Measurement of heat takes place under conditions of constant temperature, and the heat generated from the hydration reaction of cement is removed by the absorbent element. Thermocouple sensor disposed between the test sample and the absorption element records the amount of heat generated, which is proportional to the degree of reaction of the test sample.

The main advantage of this method is high precision of the method and high sensitivity in comparison with other methods, which makes it suitable method for analyzing effects of additions on cement hydration. It is relatively easy test method to conduct with low labor input. Furthermore, tests can be carried out for several samples simultaneously. It is also standardized method (NT Build 505 [39] and ASTM C1702-14 [40]). Although this method has disadvantages resulting from the necessity of using very small samples (only several grams) which practically excludes tests of mortars and concretes as well as the difficulty in measuring the heat over long periods of time, much more advantages of this method can be given. Currently, this method is often used also because of available high quality commercially manufactured equipment.

\section{Adiabatic calorimetry}

The temperature evolution of the center of the sample is measured in this method. Then, based on the known heat capacity the evolved heat is calculated. An essential element of the adiabatic calorimeter is a cooling and heating system that maintains the environment around the sample at that same temperature, so that there is no heat transfer from the sample.

The only advantage of this method is that it simulates actual conditions in massive concrete structures and allows carrying out the tests on full concrete mixtures. Much more disadvantages of this method can be specified such as no commercially available equipment, high cost and high sensitivity to the operating conditions. It is not standardized method. The results obtained are different from the isothermal calorimetry method, because the retained heat causes the hydration to accelerate and the heat evolves at a much faster rate than in an isothermal test.

\section{Semi-adiabatic calorimetry}

It is similar to adiabatic calorimetry, and the internal temperature of the sample is measured as well. However, in semi-adiabatic calorimetry, there is no control system of the ambient temperature of the sample and true adiabatic conditions are not provided. Instead, very good thermal insulation is used to maintain a condition close to adiabatic, so that heat loss to the environment is as small as possible. The output is a temperature versus time similarly as in the adiabatic test. The evolved heat is calculated based on data of temperature evolution, the known heat capacity of the sample and the amount of heat loss to the environment during the test. This method is not as sensitive as isothermal calorimetry, but it is more favorable method than adiabatic calorimetry in many respects. Primarily, the method is relatively easy to execute and the suitable equipment is available. The test can be performed on the concrete or mortar specimens. The method is also standardized (ISO 29582-2 [41], EN 196-9 [42] and NT Build 480 [43]).

There are three main problems with this method. First of all, the heat capacity of the material and heat leakage must be known to calculate the evolved hydration heat. The next disadvantage is the inability to determine the evolved heat of cement at the first contact with water because the sample preparation is usually done in an external mixer in this method. There is also the need for very frequent calibration of the device, in particular thermal capacity of the calorimeter and the coefficient of heat loss.

\section{Experimental program}

\section{Materials and test methods}

Ordinary Portland Cement CEM I 42.5R, composed of $95.7 \%$ of Portland clinker and $4.3 \%$ of limestone, was used as the main binder. Four substitution rates of OPC by ground granulated blast furnace slag or siliceous fly ash were used-10, 30, 50 and $70 \%$. In all cases, the water/ binder ratio of the cement paste was 0.5 . The chemical and mineral composition of binder components are shown in Tables 1 and 2 .

The heat of hydration was tested with the use of two methods. The isothermal measurements were carried out using TAM Air isothermal calorimeter which is an eight channel calorimeter designed for sensitive heat flow measurement. The parallel twin-chamber measuring channels are maintained at a constant temperature and one chamber 
Table 1 Chemical composition of the materials used in tests

\begin{tabular}{lclll}
\hline Component/\% & Clinker & Siliceous fly ash & Slag & Limestone \\
\hline Loss in ignition & 0.21 & 1.95 & - & 37.98 \\
Insoluble residue & 0.73 & - & - & - \\
$\mathrm{SiO}_{2}$ & 21.41 & 53.25 & 37.63 & 8.50 \\
$\mathrm{Al}_{2} \mathrm{O}_{3}$ & 5.64 & 25.05 & 6.84 & 2.61 \\
$\mathrm{Fe}_{2} \mathrm{O}_{3}$ & 2.70 & 6.65 & 1.48 & 1.44 \\
$\mathrm{CaO}$ & 65.89 & 3.86 & 45.63 & 47.34 \\
$\mathrm{MgO}$ & 1.52 & 2.78 & 5.33 & 0.72 \\
$\mathrm{SO}_{3}$ & 0.54 & 0.42 & 0.08 & 0.22 \\
$\mathrm{Na}_{2} \mathrm{O}$ & 0.10 & 1.11 & 0.55 & 0.08 \\
$\mathrm{~K}_{2} \mathrm{O}$ & 0.54 & 3.25 & 0.56 & 0.35 \\
$\mathrm{Cl}$ & 0.095 & 0.008 & 0.053 & 0.011 \\
\hline
\end{tabular}

Table 2 Mineral composition of the materials used in tests

\begin{tabular}{llll}
\hline Component/\% & Clinker & Siliceous fly ash & Slag \\
\hline $\mathrm{C}_{3} \mathrm{~S}$ & 62.8 & - & - \\
$\mathrm{C}_{2} \mathrm{~S}$ & 14.9 & - & - \\
$\mathrm{C}_{3} \mathrm{~A}$ & 10.4 & - & - \\
$\mathrm{C}_{4} \mathrm{AF}$ & 8.3 & - & - \\
Glass phase & - & 77.1 & 98.4 \\
Mullite & - & 13.0 & - \\
Quartz & - & 7.6 & - \\
Maghemite & - & 1.3 & - \\
Free CaO & 1.1 & 0.2 & - \\
$\mathrm{MgO}$ & 0.45 & 0.7 & - \\
\hline
\end{tabular}

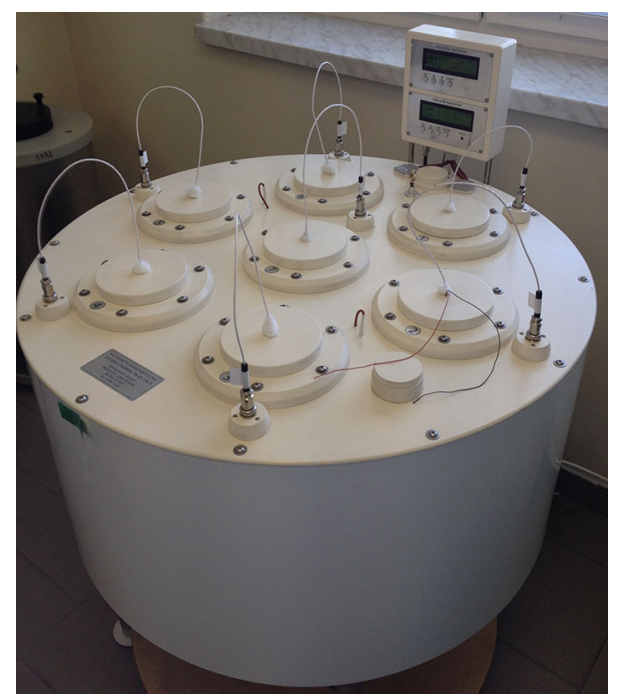

Fig. 1 Semi-adiabatic calorimeter

contains the sample, another contains the reference. The measurement was performed with $5 \mathrm{~g}$ samples of cement paste at 20 and $50{ }^{\circ} \mathrm{C}$ within $72 \mathrm{~h}$.
The heat of hydration was also determined with the use of a semi-adiabatic calorimeter (Fig. 1). The mortar sample consisted of $360 \mathrm{~g}$ of cement, $1080 \mathrm{~g}$ of sand and $180 \mathrm{~g}$ of water. Directly after mixing mortar was poured into cylindrical metal container (with volume of $800 \mathrm{~cm}^{3}$ ), and then, it was placed inside the insulated calorimeter. The temperature was registered for six tested samples, and the reference sample every $10 \mathrm{~min}$ within $72 \mathrm{~h}$. The heat of hydration is obtained by the following formula:

$Q=\frac{C}{m_{\mathrm{c}}} \Delta \theta_{\mathrm{t}}+\frac{1}{m_{\mathrm{c}}} \int_{0}^{t} \alpha \Delta \theta_{\mathrm{t}} \mathrm{d} t$

where $C$ is the total thermal capacity of the calorimeter, $\mathrm{J} \mathrm{K}{ }^{-1} ; m_{\mathrm{c}}$ is the binder mass, $g ; \Delta \theta_{\mathrm{t}}$ is the temperature difference between heating sample and ambient, $K ; \alpha$ is the total thermal loss coefficient of the calorimeter, $\mathrm{J} \mathrm{h}^{-1} \mathrm{~K}^{-1}$; $t$ is the time.

\section{Results and discussion}

\section{Effect of the type and the amount of mineral additions: isothermal test at $20{ }^{\circ} \mathrm{C}$ and semi-adiabatic test}

The typical five periods of the hydration heat evolution are described as the initial period (I), the induction period (II) the acceleration period (III), the retardation period (IV) and period of slow continued reaction $(\mathrm{V})$. A rapid heat evolution is observed during the initial period (I) which is explained by the rapid formation of an amorphous layer of hydration product around the cement particles, which separates them from the pore solution and prevents further rapid dissolution. This is followed by the induction period (II), during which almost no reaction occurs and the rate of heat evolution drops to a very low value. During the acceleration period (III), the rate of reaction increases rapidly, reaching a maximum at a time that is usually less than $24 \mathrm{~h}$ after initial mixing. This is mainly due to the hydration of the $\mathrm{C}_{3} \mathrm{~S}$ and fast formation of $\mathrm{C}-\mathrm{S}-\mathrm{H}$ gel. The rate of hydration in this period is controlled by the rate at which the hydration products nucleate and grow. After this peak, retardation period starts (period IV) and a second heat flow maximum can appear which is explained as "sulfate depletion peak" or due to renewed $\mathrm{C}_{3} \mathrm{~A}$ dissolution and an accelerated ettringite precipitation [22]. The final period $(\mathrm{V})$ is called the diffusion-limited reaction period as diffusion processes become slower and slower as the layer of hydration product around the cement particles becomes thicker and thicker.

The hydration heat evolution curves for cements with different substitution rates of slag and fly ash binders 

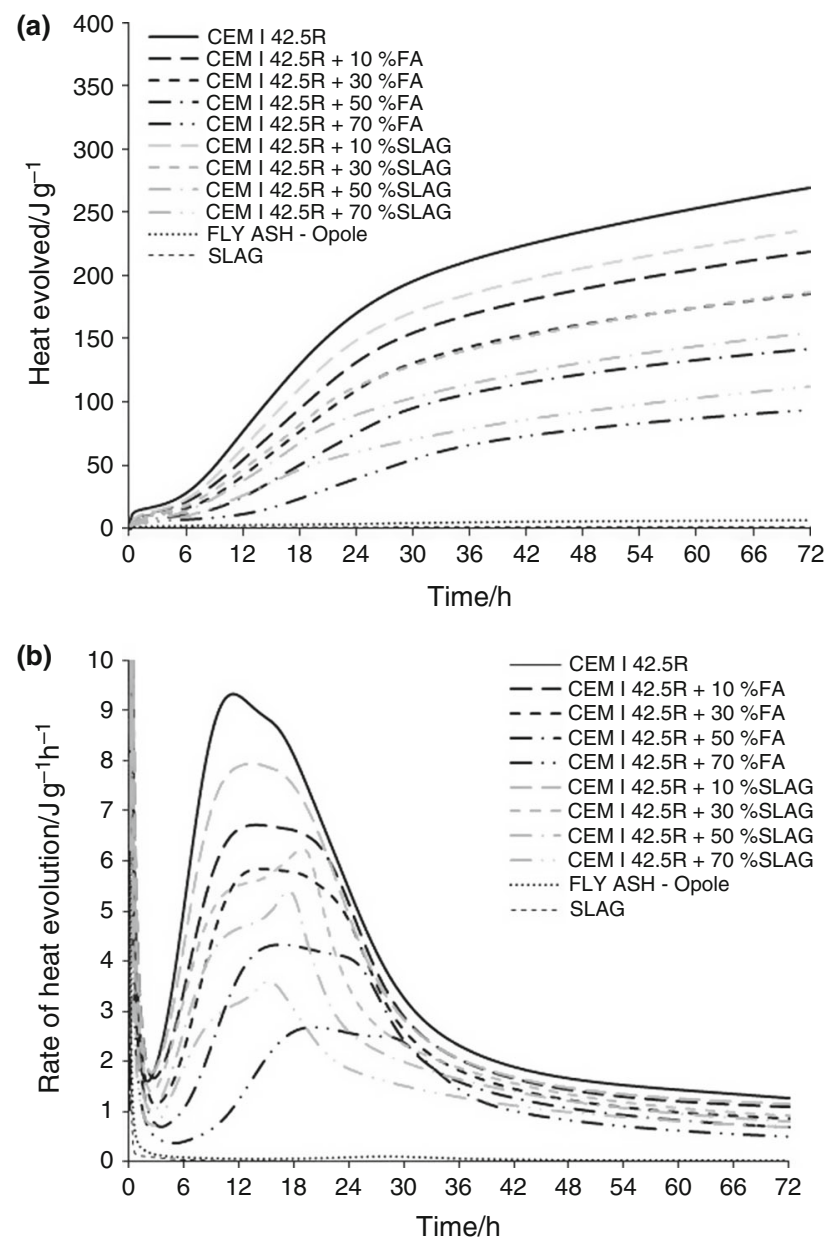

Fig. 2 The results of isothermal tests at $20{ }^{\circ} \mathrm{C}$ : heat evolved (a) and the rate of heat evolution (b) for cement-fly ash and cement-slag composite binder

measured in isothermal tests at $20{ }^{\circ} \mathrm{C}$ are shown in Fig. 2a. The rate of the hydration heat curves are shown in Fig. $2 b$. The results are also listed in Table 3. The following observations can be perceived from Table 3 and the above mentioned figures:

- The comparison of the heat of hydration of the different binders containing fly ash or slag with OPC, at $12 \mathrm{~h}$, indicates that the evolved heat of the blended cements is lower than that corresponding to the proportion of clinker contained in the blended cements. It can be seen from Table 3 that the 12 -h heat emission of cement containing $10,30,50$ and $70 \%$ of fly ash decreases by $29.3,45.5$, 67.3 and $84.8 \%$ in comparison with OPC (CEM I $42.5 \mathrm{R})$, respectively. When $10,30,50$ and $70 \%$ mass of cement was replaced by slag, the reduction in 12-h heat emission is a slightly smaller and equal, respectively, $16.9,38.8,50.6$ and $65.6 \%$ compared to OPC. In the next hours of hydration, the discussed reduction in heat is smaller and for $72 \mathrm{~h}$ it is $18.9,31.0,47.3$ and $65.1 \%$ for
$10,30,50$ and $70 \%$ fly ash content in the binder and 12.2 , $30.8,42.6$ and $58.3 \%$ for $10,30,50$ and $70 \%$ slag content. Therefore, the heat emission of cement-fly ash composite binder is less than that of composite binder containing slag at same replacement level at any time considered in these tests. It is because of the activity of fly ash which is lower than that of slag. Difference in reactivity of both materials is related to different chemical and mineral composition. Whereas slag is a latent hydraulic material, which consists mainly of amorphous phase $(>80 \%)$ with high content of $\mathrm{CaO}$ $(40-50 \%)$, the siliceous fly ash is pozzolanic material consists of glass phase (approximately 50-90\%) with low $\mathrm{CaO}$ content $(<10 \%)$ and non-reactive mineral phases such as mullite, quartz, maghemite. For reaction, fly ash requires $\mathrm{Ca}(\mathrm{OH})_{2}$ which comes from cement phases hydration $\left(\mathrm{C}_{2} \mathrm{~S}, \mathrm{C}_{3} \mathrm{~S}\right)$ and its availability controls speed of pozzolanic reaction. Tests results reported in $[44,45]$ showed that fly ash in the composite binder does not chemically react during the first 7 days, and the pozzolanic reaction and the resulting heat appears at a later period. However, there is a difference in literature about the time at which different pozzolanic materials like fly ash start to participate in the heat of hydration. Therefore, it should be remembered that the pozzolanic activity of fly ash depends on its fineness, chemical and mineral composition. The pozzolanic reaction rate is also highly dependent on the temperature [22, 32]. Consequently, the thermal effects associated with the pozzolanic reaction may occur earlier on the calorimetric curve, depending on conditions of the reaction. Additionally, the hydrolysis of clinker minerals is accelerated by alkalis, always present in fly ash [25]. As it is shown in studies $[25,28]$, it results in a situation in which the amount of hydration heat during the initial period (first $72 \mathrm{~h}$ ) is higher than would result from the degree of replacement by fly ash clinker. In case of GGBFS, high $\mathrm{pH}$ caused by $\mathrm{Ca}(\mathrm{OH})_{2}$ accelerates the dissolution reaction of glass phase and the formation of CSH phase.

- The induction period of hydration is prolonged gradually with the increased dosage of slag or fly ash. Addition of fly ash more distinctly retards the acceleratory period of cement hydration than slag, this tendency is especially clear for the high substitution rate of fly ashes. This retarding effect of the mineral additions on the cement hydration has been already reported [16-35].

- Considering the main hydration peak and its time of occurrence for different blended cements in comparison with OPC, it can be noticed that with the increased dosage of slag or fly ash, the time of maximum exothermic peak of binders is prolonged. This effect is more powerful for fly ash cement, similarly as it has 
Table 3 Characteristic values of the heat evolved

\begin{tabular}{|c|c|c|c|c|c|}
\hline \multirow[t]{2}{*}{ Sample } & \multirow{2}{*}{$\begin{array}{l}\text { Temperature/testing } \\
\text { method }\end{array}$} & \multicolumn{3}{|c|}{ Heat evolved/J $\mathrm{g}^{-1}$} & \multirow{2}{*}{$\begin{array}{l}\text { Peak value of } \\
\text { heat evolution } \\
\text { rate } / \mathrm{J} \mathrm{g}^{-1} \mathrm{~h}^{-1}\end{array}$} \\
\hline & & $12 \mathrm{~h}$ & $41 \mathrm{~h}$ & $72 \mathrm{~h}$ & \\
\hline \multirow[t]{3}{*}{ CEM I 42.5R (OPC) } & $20{ }^{\circ} \mathrm{C}-\mathrm{IS}$ & 76.6 & 222.2 & 269.1 & 9.3 \\
\hline & $50{ }^{\circ} \mathrm{C}-\mathrm{IS}$ & 247.3 & 311.5 & 319.3 & 42.5 \\
\hline & SA & 202.3 & 351.8 & 366.5 & 42.8 \\
\hline \multirow[t]{3}{*}{ CEM I 42.5R + $10 \%$ FA } & $20^{\circ} \mathrm{C}-\mathrm{IS}$ & 54.2 & 177.9 & 218.2 & 6.7 \\
\hline & $50{ }^{\circ} \mathrm{C}$ - IS & 183.2 & 251.7 & 266.2 & 28.6 \\
\hline & SA & 136.5 & 297.1 & 325.1 & 31.2 \\
\hline \multirow[t]{3}{*}{ CEM I 42.5R + 30 \% FA } & $20{ }^{\circ} \mathrm{C}-\mathrm{IS}$ & 41.7 & 152.1 & 185.7 & 5.8 \\
\hline & $50{ }^{\circ} \mathrm{C}$ - IS & 168.6 & 230.9 & 248.3 & 31.3 \\
\hline & SA & 91.1 & 238.5 & 267.1 & 19.6 \\
\hline \multirow[t]{3}{*}{ CEM I $42.5 \mathrm{R}+50 \% \mathrm{FA}$} & $20{ }^{\circ} \mathrm{C}$-IS & 25.1 & 113.8 & 141.9 & 4.3 \\
\hline & $50{ }^{\circ} \mathrm{C}-\mathrm{IS}$ & 102.4 & 155.1 & 172.6 & 16.2 \\
\hline & SA & 50.6 & 171.2 & 200.2 & 12.0 \\
\hline \multirow[t]{3}{*}{ CEM I 42.5R + $70 \%$ FA } & $20^{\circ} \mathrm{C}-\mathrm{IS}$ & 11.6 & 72.1 & 93.8 & 2.7 \\
\hline & $50{ }^{\circ} \mathrm{C}-\mathrm{IS}$ & 57.1 & 88.8 & 94.5 & 8.3 \\
\hline & SA & 22.3 & 92.9 & 112.5 & 5.9 \\
\hline \multirow[t]{3}{*}{ CEM I 42.5R + $10 \%$ SLAG } & $20^{\circ} \mathrm{C}-\mathrm{IS}$ & 63.6 & 194.6 & 236.2 & 7.9 \\
\hline & $50{ }^{\circ} \mathrm{C}-\mathrm{IS}$ & 217.8 & 294.2 & 309.6 & 39.7 \\
\hline & SA & 144.2 & 304.8 & 334.5 & 27.7 \\
\hline \multirow[t]{3}{*}{ CEM I 42.5R + $30 \%$ SLAG } & $20^{\circ} \mathrm{C}-\mathrm{IS}$ & 46.9 & 149.8 & 186.2 & 6.3 \\
\hline & $50{ }^{\circ} \mathrm{C}-\mathrm{IS}$ & 162.3 & 232.8 & 249.9 & 27.2 \\
\hline & SA & 79.4 & 219.8 & 255.6 & 16.9 \\
\hline \multirow[t]{3}{*}{ CEM I 42.5R + $50 \%$ SLAG } & $20{ }^{\circ} \mathrm{C}-\mathrm{IS}$ & 37.9 & 121.9 & 154.5 & 5.4 \\
\hline & $50{ }^{\circ} \mathrm{C}-\mathrm{IS}$ & 129.7 & 195.7 & 213.5 & 18.9 \\
\hline & SA & 65.4 & 186.8 & 231.8 & 12.4 \\
\hline \multirow[t]{3}{*}{ CEM I 42.5R + $70 \%$ SLAG } & $20{ }^{\circ} \mathrm{C}-\mathrm{IS}$ & 26.3 & 85.0 & 112.1 & 3.6 \\
\hline & $50{ }^{\circ} \mathrm{C}-\mathrm{IS}$ & 94.4 & 152.5 & 170.5 & 13.8 \\
\hline & SA & 53.7 & 122.2 & 152.6 & 6.9 \\
\hline
\end{tabular}

$I S$ isothermal method, $S A$ semi-adiabatic method

been in case of the induction period retardation. All curves plotted in Fig. 2 show that the heat of hydration decreases when the substitution rate of mineral additions increases. Consequently, the smaller peak value of the second exothermic peak is observed for more content of mineral addition.

- The main hydration peak significantly decreased with increasing amount of mineral addition. The rate of hydration heat at the second local maximum decreases almost proportionally with the increase in fly ash compared with OPC except cement containing $10 \%$ of fly ash for which this reduction is greater. The second local maximum on the rate of heat evolution curve (Fig. 2b) in case of cement-fly ash composite binder was reduced by $27.9,37.3,53.6$ and $71.2 \%$ for the replacement rate of cement by fly ash 10,30, 50 and $70 \%$, respectively. For cement-slag composite binder, the main hydration peak was reduced by $14.8,33,42.1$ and $61.5 \%$ for cement with 10, 30, 50 and $70 \%$ of slag replacement. This reduction is lower for slag cement. The time of occurrence of the second local maximum is also delayed with the increasing rate of the clinker replacement by fly ash or slag.

Generally, most of the above statements are also valid for test results obtained from the semi-adiabatic tests. Therefore, the curves plotted in Fig. 3 shows that the evolved heat decreases when the substitution rate of slag or fly ash increases. The induction period of hydration binder as well as the time of occurrence of the second local maximum is prolonged gradually with the increased dosage of mineral addition. In case of cement-fly ash composite binder with 10,50 and $70 \%$ substitution rates, the heat emission is lower than that related to the same substitution rates of cement by slag (Fig. 3a). Simultaneously, this effect is most pronounced in the case of $70 \%$ of clinker 


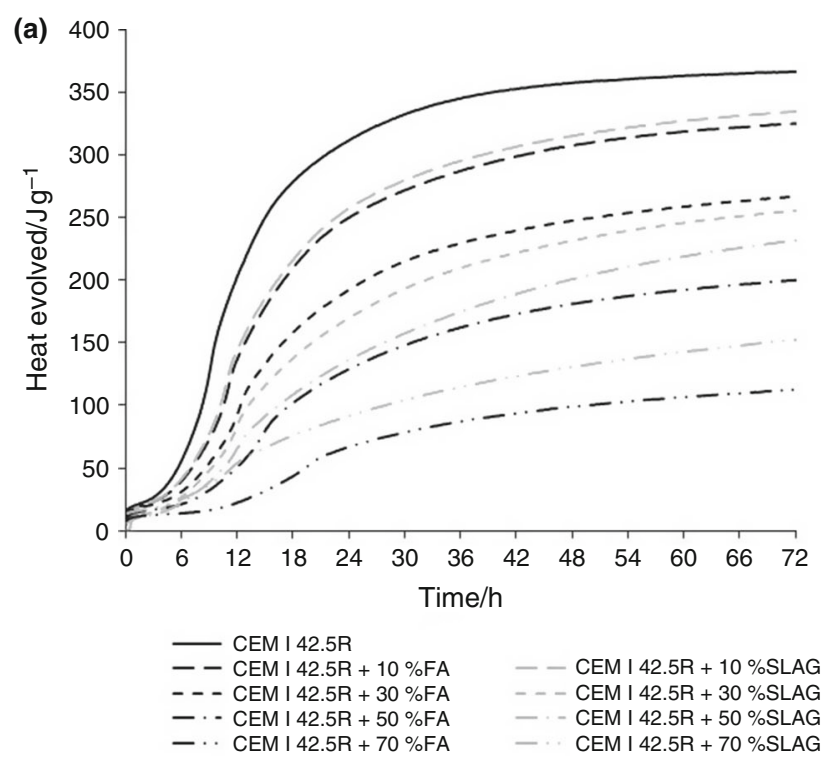

(b)

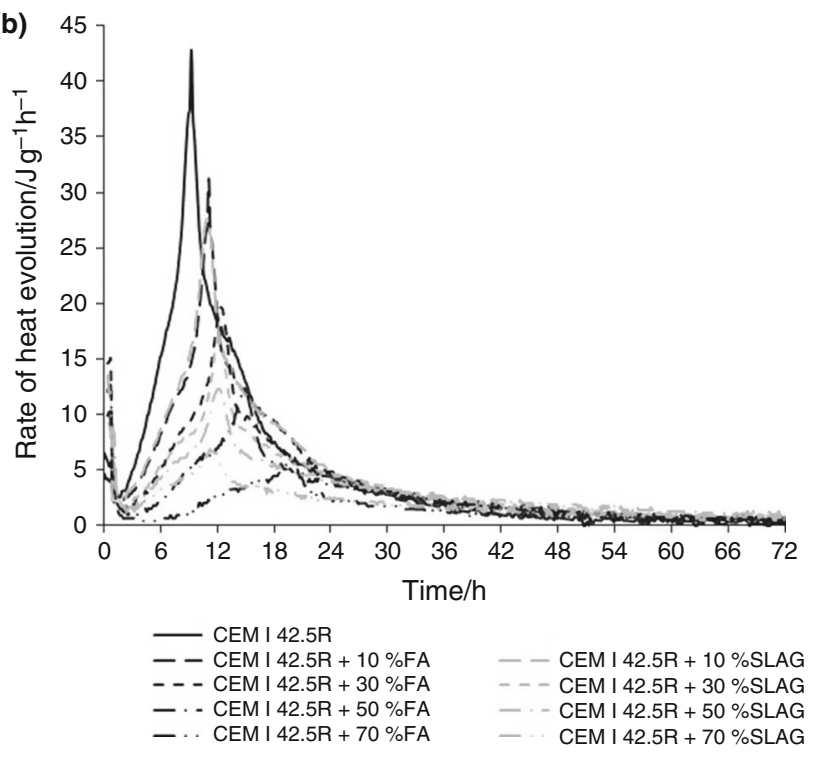

Fig. 3 The results of semi-adiabatic tests: heat evolved (a) and the rate of heat evolution (b) for cement-fly ash and cement-slag composite binder

replacement by the fly ash and it is almost imperceptible for $10 \%$ of fly ash content. Interestingly, for $30 \%$ content of the mineral additions, the higher heat emission was registered for fly ash-cement than for slag-cement. The main hydration peak also decreased with increasing amount of mineral addition, but there are no evident differences between obtained peak values for fly ash and slag cement (Fig. 3b). However, there is the difference in time of occurrence of the main hydration peak which is delayed much more in case of fly ash-cement. The specified features may be probably related to the effects of temperature, which is a variable in the semi-adiabatic tests and affects the hydration process.

\section{Effect of temperature}

The isothermal tests results obtained at 20 and $50{ }^{\circ} \mathrm{C}$ plotted in Fig. 4 and listed in Table 3 can be highlighted in the following points:

- Figure 4a, c shows the total heat emission produced during the whole studied time period of $72 \mathrm{~h}$. A substantial heat emission increase when the hydration temperature rises from 20 to $50{ }^{\circ} \mathrm{C}$ can be noted. It can be also seen that the hydration in the first hours is more sensitive to the temperature. At the same time, the raising temperature promotes the early hydration of composite binder more than that of OPC. When the different types of mineral additions are compared, fly ash can be perceived as more sensitive to higher temperature at the first hours of hydration. The quantitative comparison made on the basis of Table 3 confirms these observations. In case of OPC, the 12-, 41- and 72-h heat emissions are 3.2, 1.4 and 1.2 times higher at $50{ }^{\circ} \mathrm{C}$ as compared with the corresponding values of heat measured at $20^{\circ} \mathrm{C}$. The heat emission of cement containing $10 \%$ of fly ash or slag at $50{ }^{\circ} \mathrm{C}$ increases almost exactly in the same way: 3.4 for $12 \mathrm{~h}$, $1.4-1.5$ for $41 \mathrm{~h}$ and 1.3 for $72 \mathrm{~h}$ of curing. For cement with the higher content of mineral addition $(30,50,70 \%)$, more significant increase in generated heat can be noticed for cement with fly ash, but only for the first $12 \mathrm{~h}$ of hydration. For example, in case of cement with $70 \%$ of fly ash, the 12-, 41- and 72-h heat emissions are 4.9, 1.2 and 1.0 times higher at $50{ }^{\circ} \mathrm{C}$ as compared with the corresponding values of heat measured at $20{ }^{\circ} \mathrm{C}$. When $70 \%$ mass of cement was replaced by slag, the relating values 3.6, 1.8 and 1.5 are obtained for the corresponding periods. For all replacement rates of cement by fly ash or slag, the increase in heat after $72 \mathrm{~h}$ is very similar and ranges from 1.2 (50\% fly ash) to 1.5 (70 \% slag). For cement with $70 \%$ of fly ash, the heat after $72 \mathrm{~h}$ at $50{ }^{\circ} \mathrm{C}$ is the identical to that at $20{ }^{\circ} \mathrm{C}$.

- When the hydration temperature increases from 20 to $50{ }^{\circ} \mathrm{C}$, the induction period is shortened significantly for all binders with different fly ash-cementitious or slag-cementitious material ratio. Consequently, the time reaching the second exothermic peak of binders is shortened by about $6 \mathrm{~h}$ for all investigated cements.

- At $50{ }^{\circ} \mathrm{C}$, the second exothermic peak forms with a very narrow shape and the peak value increases greatly. The maximum value of the second exothermic effect of binders increases, but a clear relationship between the amount of addition and peak growth cannot be identified. From Table 3, the following growth of the maximum values of the second exothermic effect can be detected: for composite binder containing 10, 30, 50 and $70 \%$ of fly ash it is 4.3, 5.4, 3.8 and 3.1 times with 

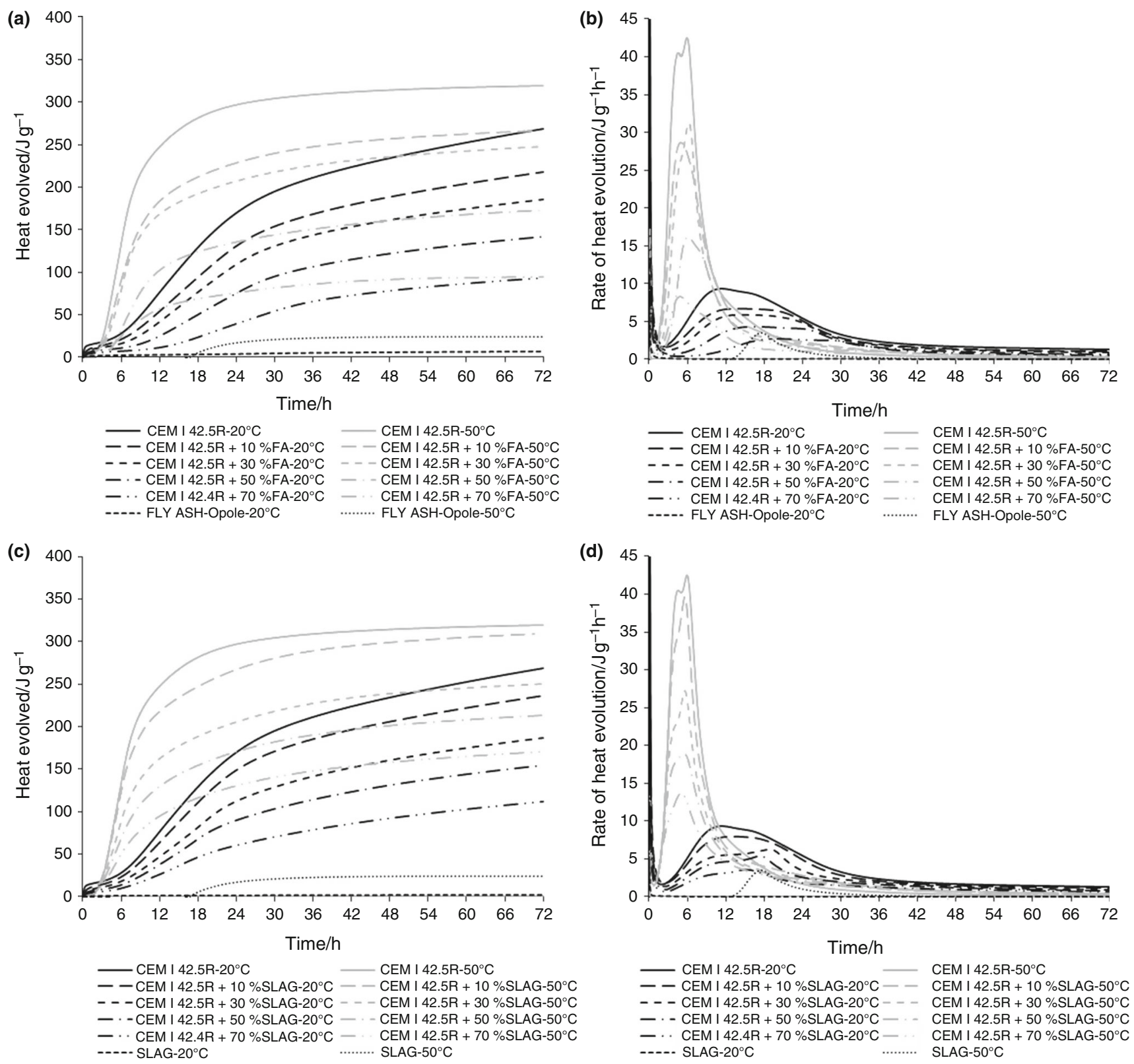

Fig. 4 The results of isothermal tests at 20 and $50{ }^{\circ} \mathrm{C}$ : heat evolved for cement-fly ash composite binder (a), the rate of heat evolution of cement-fly ash composite binder (b), heat evolved for cement-slag

the temperature increasing from 20 to $50{ }^{\circ} \mathrm{C}$ and for composite binder containing $10,30,50$ and $70 \%$ of slag it is 5.0, 4.3, 3.5 and 3.8 times. In case of OPC, the second exothermic peak increased 4.6 times at $50{ }^{\circ} \mathrm{C}$.

\section{Conclusions}

The early-stage hydration heat characteristics of a composite binder with four substitution rates of cement by ground granulated blast furnace slag or siliceous fly ash $(10,30,50$ and $70 \%)$ have been studied in a dependence

composite binder (c), the rate of heat evolution of cement-slag composite binder (d)

on testing method and temperature. The reference Portland cement has been also investigated. The main results of the heat of hydration presented in this article can be summarized as follows:

- The evolved heat of composite binder decreases with the increase in mineral addition.

- The heat emission of cement-fly ash composite binder is less than that of composite binder containing slag at same replacement level at considered time of $72 \mathrm{~h}$.

- This retarding effect of the mineral additions on the cement hydration was confirmed. The time of the 
acceleration period of cement hydration and maximum exothermic peak of binders is prolonged. This effect is more powerful for fly ash cement and especially clear for the high substitution rate of fly ashes.

- The main hydration peak significantly decreased with increasing amount of mineral addition. The rate of hydration heat at the second local maximum decreases almost proportionally with the increase in fly ash compared with OPC, for slag cement this reduction is lower.

- The hydration of composite binder is accelerated at $50{ }^{\circ} \mathrm{C}$. The promotion effect of the elevated temperature on the hydration of composite binder containing mineral additions is greater than that of OPC. The hydration in the first hours is more sensitive to the temperature. The greater increase in generated heat at $50{ }^{\circ} \mathrm{C}$ was noted for cement with fly ash, but only for the first $12 \mathrm{~h}$ of hydration.

- At the temperature $50{ }^{\circ} \mathrm{C}$, the end of induction period and the time of the second peak are shortened significantly. Simultaneously, the second exothermic peak has a very narrow shape and the peak value increases greatly, but a clear relationship between the amount of addition and peak growth has not been established.

Open Access This article is distributed under the terms of the Creative Commons Attribution 4.0 International License (http://creativecommons.org/licenses/by/4.0/), which permits unrestricted use, distribution, and reproduction in any medium, provided you give appropriate credit to the original author(s) and the source, provide a link to the Creative Commons license, and indicate if changes were made.

\section{References}

1. ACI Committee 207. ACI 207.1R-05: guide to mass concrete. ACI manual of concrete practice, Part 1; 2005.

2. RILEM TC 119-TCE. Recommendations of TC 119-TCE: avoidance of thermal cracking in concrete at early ages. Mater Struct. 1997;30(202):451-64.

3. Report 25: Early age cracking in cementitious systems. Report of RILEM Technical Committee 181-EAS, Bentur A, editors. RILEM Publications; 2002.

4. Mihashi H, Leite JP. State-of-the-art report on control cracking in early age concrete. J Adv Concr Technol. 2004;2(2):141-54.

5. Briffaut M, Benboudjema F, Torrenti JM, Nahas G. Effects of the early age thermal behaviour on long term damage risks in massive concrete structures. Eur J Environ Civ Eng. 2012;16(5):589-605.

6. Zreiki J, Bouchelaghema F, Chaouchea M. Early-age behaviour of concrete in massive structures-experimentation and modelling. Nucl Eng Des. 2010;240:2643-54.

7. Benboudjema F, Torrenti JM. Early-age behaviour of concrete nuclear containments. Nucl Eng Des. 2008;238(10):2495-506.

8. Klemczak B, Knoppik-Wróbel A. Early age thermal and shrinkage cracks in concrete structures-description of the problem. Archit Civ Eng Environ. 2011;4(2):35-48.
9. Klemczak B, Knoppik-Wróbel A. Early age thermal and shrinkage cracks in concrete structures-influence of curing conditions. Archit Civ Eng Environ. 2011;4(4):47-58.

10. Klemczak B, Knoppik-Wróbel A. Early age thermal and shrinkage cracks in concrete structures-influence of geometry and dimension of a structure. Archit Civ Eng Environ. 2011;4(3):55-70.

11. Roy DM, Idorn GM. Hydration, structure, and properties of blast furnace slag cements, mortars, and concrete. ACI Mater J. 1982;79(6):444-57.

12. De Schutter G, Taerwe L. General hydration model for Portland cement and blast furnace slag cement. Cem Concr Res. 1995;25:593-604.

13. De Schutter G. Hydration and temperature development of concrete made with blast-furnace slag cement. Cem Concr Res. 1999;29:143-9.

14. Escalante JI, Gomez LY, Johal KK, Mendoza G, Mancha H, Mendez J. Reactivity of blast-furnace slag in Portland cement blends hydrated under different conditions. Cem Concr Res. 2001;31:1403-9.

15. Saeki T, Monteiro PJM. A model to predict the amount of calcium hydroxide in concrete containing mineral admixtures. Cem Concr Res. 2005;35:1914-21.

16. Pane I, Hansen W. Investigation of blended cement hydration by isothermal calorimetry and thermal analysis. Cem Concr Res. 2005;35:1155-64.

17. Binici H, Temiz H, Kose MM. The effect of fineness on the properties of the blended cements incorporating ground granulated blast furnace slag and ground basaltic pumice. Cem Concr Res. 2007;27:1122-8.

18. Meinhard K, Lackner R. Multi-phase hydration model for prediction of hydration-heat release of blended cements. Cem Concr Res. 2008;38:794-802.

19. Ježo L, Ifka T, Cvopa B, Škundova J, Vladimir K, Palou MT. Effect of temperature upon the strength development rate and upon the hydration kinetics of cements. Ceram Silik. 2010;54:269-76.

20. Chen X, Fang K, Yang H, Peng H. Hydration kinetics of phosphorus slag-cement paste. J Wuhan Univ Technol Mater Sci. 2011;26:142-6.

21. Merzouki T, Bouasker M, Khalifa N, Mounanga P. Contribution to the modeling of hydration and chemical shrinkage of slag-blended cement at early age. Constr Build Mater. 2013;44:368-80.

22. Han F, Liu R, Wang D, Yan P. Characteristics of the hydration heat evolution of composite binder at different hydrating temperature. Thermochim Acta. 2014;586:52-7.

23. Gruyaert E, Robeyst N, De Belie N. Study of the hydration of Portland cement blended with blast-furnace slag by calorimetry and thermogravimetry. J Therm Anal Calorim. 2010;102:941-51.

24. Siler P, Kratky J, De Belie N. Isothermal and solution calorimetry to assess the effect of superplasticizers and mineral admixtures on cement hydration. J Therm Anal Calorim. 2012;107:313-20.

25. Nocuń-Wczelik W. Heat evolution in hydrated cementitious systems admixtured with fly ash. J Therm Anal Calorim. 2001;65:613-9.

26. Nocuń-Wczelik W, Trybalska B, Żugaj E. Application of calorimetry as a main tool in evaluation of the effect of carbonate additives on cement hydration. $\mathrm{J}$ Therm Anal Calorim. 2013;113:351-6.

27. Nocuń-Wczelik W, Łagosz A, Kowalski B, Gawlicki M. Calorimetry in testing waste materials from the brown coal combustion. J Therm Anal Calorim. 2014;118:123-31.

28. Pacewska B, Blonkowski G, Wilińska I. Investigations of the influence of different fly ashes on cement hydration. J Therm Anal Calorim. 2006;86:179-86.

29. Pacewska B, Wilińska I, Nowacka M. Studies on the influence of different fly ashes and Portland cement on early hydration of calcium aluminate cement. J Therm Anal Calorim. 2011;106:859-68. 
30. Pacewska B, Wilińska I. Calorimetric and thermal analysis studies on the influence of waste aluminosilicate catalyst on the hydration of fly ash-cement paste. J Therm Anal Calorim. 2014;116:689-97.

31. Giergiczny Z. Effect of some additives on the reactions of fly ash-Ca(OH $)_{2}$ system. J Therm Anal Calorim. 2004;76:747-54.

32. Giergiczny Z. Popiół lotny w składzie cementu i betonu (Fly Ash in cement and concrete). Monograph: Silesian University of Technology; 2013.

33. Kumar M, Singh SK, Singh NP. Heat evolution during the hydration of Port-land cement in the presence of fly ash, calcium hydroxide and super plasticizer. Thermochim Acta. 2012;548: 27-32.

34. Narmluk M, Nawa T. Effect of fly ash on the kinetics of Portland cement hydration at different curing temperature. Cem Concr Res. 2011;41(6):579-89.

35. Mounanga P, Khokhar MIA, Hachem RE, Loukili A. Improvement of the early-age reactivity of fly ash and blast furnace slag cementitious systems using limestone filler. Mater Struct. 2011; 44(2):437-53.

36. ISO 29582-1:2009. Methods of testing cement. Determination of the heat of hydration. Part I: Solution method.
37. EN 196-8:2010. Methods of testing cement. Heat of hydration. Solution method.

38. ASTM C186-13. Standard test method for heat of hydration of hydraulic cement.

39. NT Build 505. Measurement of heat of hydration of cement with heat conduction calorimetry.

40. ASTM C1702-14. Standard test method for measurement of heat of hydration of hydraulic cementitious materials using isothermal conduction calorimetry.

41. ISO 29582-2:2009. Methods of testing cement. Determination of the heat of hydration. Part II: semi-adiabatic method.

42. EN 196-9:2010. Methods of testing cement. Heat of hydration. Semi-adiabatic method

43. NT Build 480. Cement: heat of hydration.

44. Sakai E, Miyahara S, Ohsawa S, Lee SH, Daimon M. Hydration of fly ash cement. Cem Concr Res. 2005;3(6):1135-40.

45. Singh NB, Kalra M, Kumar M, Rai S. Hydration of ternary cementitious system: Portland cement, fly ash and silica fume. J Therm Anal Calorim. 2014;119(1):381-9. 